\title{
Partial Molar Volumes of Aluminium Chloride, Aluminium Sulphate and Aluminium Nitrate in Water-rich Binary Aqueous Mixtures of Tetrahydrofuran
}

\author{
R.C.THAKUR ${ }^{1 *}$, RAVI SHARMA ${ }^{1}$, ASHISH KUMAR $^{1}$, SANJAY KUMAR $^{1}$ and M.L.PARMAR ${ }^{2}$ \\ ${ }^{1}$ Department of Chemistry, School of Physical Sciences, Lovely Professional University, Punjab \\ ${ }^{3}$ Department of Chemistry, HPU Shimla, India. \\ ${ }^{*}$ Corresponding author E-mail: rameshchandthakur@yahoo.co.in
}

http://dx.doi.org/10.13005/ojc/300469

(Received: October 01, 2014; Accepted: November 20, 2014)

\begin{abstract}
Partial molar volumes of aluminium chloride, aluminium sulphate and aluminium nitrate have been determined in water rich binary aqueous mixtures of tetrahydrofuran $(5,10,15,20 \%$ by weight of tetrahydrofuran) with the help of density measurements. The density measurements were made by using Ward and Millero method and results have been analysed by Masson's equation and interpreted in terms of ion-ion or ion -solvent interactions. The partial molar volumes vary with temperature as a power series of temperature. Structure making or breaking capacities of aluminium salts have been inferred from the sign $\left(\frac{\partial^{2} \phi_{v}^{0}}{\partial T^{2}}\right) p$ i.e second derivative of partial molar volume with respect to temperature at constant pressure. The aluminium salts have been found as structure breakers in binary aqueous mixture of tetrahydrofuran.
\end{abstract}

Key words: THF, partial molar volumes, solution chemistry, structure breaker, aluminium salts

\section{INTRODUCTION}

Partial molar volume is one of the important thermodynamic property which has been proved a very useful tool in determining the various types of interactions like ion-ion, ion - solvent and solvent -solvent interactions occurring in aqueous as well as non-aqueous solutions ${ }^{1-11}$. These interactions are very helpful in determining the structure and properties of the solutions. On the addition of an organic solvent to water, it brings a change in the solvation of ions. Recently, appreciable work has been done on thermodynamic properties of various electrolytes in different binary aqueous mixtures but studies of aluminium salts in binary aqueous mixtures of tetrahydrofuran are still missing. Hence, the present study seeks an attempt to understand the interactions of aluminium salts in water and THF+ water system. 


\section{EXPERIMENTAL}

The reagents, aluminium chloride, aluminium sulphate and aluminium nitrate were taken of AR grade. All these reagents were used after drying over calcium oxide desiccator to keep them in dry atmosphere. Fresh triple distilled water was used as standard solvent for preparing binary $\mathrm{THF}+$ water mixture. The density of dioxane was found $1.02250 \mathrm{gcm}^{-3}$ at $303.15 \mathrm{~K}$, is in good agreement with literature value of THF density value $^{12}\left(\mathrm{~d}=1.02230 \mathrm{gm}^{-3}\right)$.

The binary aqueous mixtures of tetrahydrofuran and six different concentrations of above mentioned aluminium salts were prepared by weight and the conversion of molality $(\mathrm{m})$ into molar concentration(c) was done by using the standard expression:

$$
c=\frac{\mathrm{md} 1000}{1000+\mathrm{mM}_{2}}
$$

Where, $d$ is the density of solution and $M_{2}$ is the molecular weight of aluminium salts.

The density was measured with the help of an apparatus similar to the one reported by Ward and Millero ${ }^{13}$. The accuracy in the density measurements was $1 \times 10^{-4} \mathrm{gcm}^{-3}$.

The apparent molar volumes (v) were calculated from the density data using the following expression $^{14}$

$$
v=\frac{1000\left(\mathrm{~d}^{0}-\mathrm{d}\right)}{\operatorname{mdd}_{0}}+\frac{M_{2}}{d^{0}}
$$

where $\mathrm{d}_{0}$ is the density of THF + water as solvent and d is the density of solution; $\mathrm{c}$ is the molar concentration of aluminium salts and $M_{2}$ is the molecular weight of aluminium salts. The density measurements were taken in a well stirred water bath with a temperature control of $\pm 0.01 \mathrm{~K}$.

\section{RESULTS AND DISCUSSION}

The measured values of densities of aqueous solutions of aluminium salts in different compositions of THF + water $(5,10,15,20 \%)$ at $303.15 \mathrm{~K}$, have been used to calculate the limiting molar volumes. The plot of verses $\sqrt{ } \mathrm{c}$ were found to be linear with positive slopes in different compositions of THF + water. A sample plot for aluminium nitrate in different compositions of THF + water at $303.15 \mathrm{~K}$ is shown in fig. 1

The limiting molar volumes $\varphi^{0}$ and experimental slopes $S_{v}{ }^{*}$ were calculated by using Masson equation

$$
\phi_{v}=\phi_{v}^{0}+s_{v}^{*} c^{1 / 2}
$$

Table 1 shows the values of ${ }_{v}^{0}$ and $S_{v}{ }^{*}$, calculated in different compositions of binary aqueous mixture of THF at $303.15 \mathrm{~K}$. It is clear from table 1 , that the values of slopes $\left(S_{V}{ }^{*}\right)$ are negative in water as well as in $\mathrm{THF}+$ water mixture at $303.15 \mathrm{~K}$ in all the compositions. The negative slopes values of aluminium salts, indicates the presence of weak ion- ion interactions. Also, from Table 1, it is clear that the magnitude of $S_{v}{ }^{*}$ values of aluminium salts decreases with increase in the amount of THF in water, which shows that ion-ion interactions are further weakened which results in the increase in solvation. Also from Table 1 , it is clear that ${ }_{v}$ the values are positive and increase in magnitude, in all the compositions of THF + water at $303.15 \mathrm{~K}$ for aluminium salts taken for study. The ${ }_{\mathrm{v}}^{0}$ values which is a measure of ion-solvent interaction increases for each aluminium salts with the increase of THF amount in water, shows that ion-solvent interactions enhanced on the addition of THF in water which indicates that solvent has less affinity for water. On comparing the magnitudes of values with the values of ${ }_{v}$, values are more in magnitudes than that of the same aluminium salts. This concludes that ionsolvent interactions dominate over the ion-ion interactions in water + THF mixture at $303.15 \mathrm{~K}$.

The volume of transfer $\left(\Delta v_{(\text {tr })}^{0}\right)$ has also been calculated by using the relation:

$$
\Delta \mathrm{V}_{(\mathrm{tr})}^{0}=\Delta_{\mathrm{v}(\mathrm{MS})}^{0}-{ }_{\mathrm{v}(\mathrm{W})}^{0}
$$

Here ${ }^{0}{ }_{\mathrm{V}}$ (MS) and ${ }_{\mathrm{v}(\mathrm{W})}^{0}$ are the partial molar volumes of aluminium salts in mixture of THF + water and water as solvents respectively. The values of volume of transfer of aluminium salts were recorded 
in table 1.It is clear from table 1 that the $\Delta \mathbf{v}^{0}{ }_{(t r)}$ values continuously increase in magnitude with the increase in the content of THF in water. The increase in ${ }^{0}$ and $\Delta v^{0}{ }_{\text {(tr) }}$ may be trait to the decrease in electrostriction in the presence of THF. The electrostriction effect, which leads to the contraction in the volume of the solvent, is lowered in the mixed solvents as compared with that in pure water. This electrostriction effect, again confirming the earlier conclusion of lesser affinity of THF for water. $\Delta \mathrm{v}^{0}{ }_{(\mathrm{tr})}$ values, for each aluminium salts rise with the increase of THF amount in water; which may be trait to the decrease in solvent - solvent interactions between THF + water.

Since the behaviour of each electrolyte was found to be linear and same in different composition of THF + water at $303.15 \mathrm{~K}$, so only

Table 1: Partial molar volumes $\left(\phi_{v}{ }^{\circ}\right)$ and experimental slopes $\left(s_{v}{ }^{*}\right)$ for aluminium sulphate, aluminium nitrate and aluminium chloride in different compositions of THF+water at $\mathbf{3 0 3 . 1 5} \mathbf{k}$ temperature

\begin{tabular}{|c|c|c|c|c|c|c|c|c|c|}
\hline \multirow{2}{*}{$\begin{array}{l}\text { Composition } \\
\text { of THF- } \\
\text { Water (wt.\% ) }\end{array}$} & \multicolumn{3}{|c|}{$\begin{array}{l}\text { Aluminium } \\
\text { Sulphate }\end{array}$} & \multicolumn{3}{|c|}{$\begin{array}{c}\text { Aluminium } \\
\text { Nitrate }\end{array}$} & \multicolumn{3}{|c|}{$\begin{array}{c}\text { Aluminium } \\
\text { Chloride }\end{array}$} \\
\hline & $\begin{array}{c}\phi_{\mathrm{v}}^{\circ} \\
\left(\mathrm{cm}^{3}\right. \\
\left.\mathrm{mol}^{-1}\right)\end{array}$ & $\begin{array}{c}\mathrm{Sv}^{*} \\
\left(\mathrm{~cm}^{3} \mathrm{It}^{1 / 2}\right. \\
\left.\mathrm{mol}^{-3 / 2}\right)\end{array}$ & $\begin{array}{l}\Delta \mathrm{V}_{\mathrm{tr}}^{0} \\
\left(\mathrm{~cm}^{3}\right. \\
\left.\mathrm{mol}^{-1}\right)\end{array}$ & $\begin{array}{c}\phi_{\mathrm{v}}{ }^{\circ} \\
\left(\mathrm{cm}^{3}\right. \\
\left.\mathrm{mol}^{-1}\right)\end{array}$ & $\begin{array}{c}\mathrm{Sv}^{*} \\
\left(\mathrm{~cm}^{3} \mathrm{It}^{1 / 2}\right. \\
\left.\mathrm{mol}^{-3 / 2}\right)\end{array}$ & $\begin{array}{l}\Delta \mathrm{V}_{\mathrm{tr}}^{0} \\
\left(\mathrm{~cm}^{3}\right. \\
\left.\mathrm{mol}^{-1}\right)\end{array}$ & $\begin{array}{c}\phi_{\mathrm{v}}^{\circ} \\
\left(\mathrm{cm}^{3}\right. \\
\left.\mathrm{mol}^{-1}\right)\end{array}$ & $\begin{array}{c}\mathrm{Sv}^{*} \\
\left(\mathrm{~cm}^{3} \mathrm{It}^{1 / 2}\right. \\
\left.\mathrm{mol}^{-3 / 2}\right)\end{array}$ & $\begin{array}{l}\Delta \mathrm{V}^{0}{ }_{\mathrm{tr}} \\
\left(\mathrm{cm}^{3}\right. \\
\left.\mathrm{mol}^{-1}\right)\end{array}$ \\
\hline 0 & 599.83 & -2.572 & - & 307.14 & -2.668 & - & 166.08 & -1.948 & - \\
\hline 5 & 610.80 & -3.637 & 10.97 & 316.22 & -3.139 & 09.08 & 179.10 & -2.398 & 13.02 \\
\hline 10 & 617.92 & -3.935 & 18.09 & 335.75 & -3.562 & 28.61 & 184.81 & -2.414 & 18.73 \\
\hline 15 & 633.60 & -4.391 & 33.77 & 355.80 & -3.731 & 48.66 & 196.03 & -2.664 & 29.95 \\
\hline 20 & 644.32 & -4.885 & 44.49 & 366.20 & -3.886 & 59.06 & 202.09 & -2.749 & 36.01 \\
\hline
\end{tabular}

Table 2: Partial molar volumes $\left(\phi_{v}{ }^{\circ}\right)$ and experimental slopes $\left(s_{v}^{*}\right)$ for aluminium sulphate, aluminium nitrate, aluminium chloride in $5 \%(w / w)$ thf+water at different temperatures

\begin{tabular}{|c|c|c|c|c|c|c|}
\hline \multirow{2}{*}{$\begin{array}{l}\text { Temperature } \\
\text { (k) }\end{array}$} & \multicolumn{2}{|c|}{ Aluminium sulphate } & \multicolumn{2}{|c|}{ Aluminium nitrate } & \multicolumn{2}{|c|}{ Aluminium chloride } \\
\hline & $\begin{array}{c}\phi_{\mathrm{v}}{ }^{0} \\
\left(\mathrm{~cm}^{3} \mathrm{~mol}^{-1}\right.\end{array}$ & $\begin{array}{c}\mathrm{S}_{\mathrm{v}}{ }^{*} \\
\mathrm{n}^{3} \mathrm{lit}^{1 / 2} \mathrm{mo}\end{array}$ & $\begin{array}{c}\phi_{\mathrm{v}}{ }^{0} \\
\left(\mathrm{~cm}^{3} \mathrm{~mol}^{-1}\right)\end{array}$ & $\begin{array}{c}\mathrm{S}_{\mathrm{v}}{ }^{*} \\
\left(\mathrm{~m}^{3} \mathrm{lit}^{1 / 2} \mathrm{~mol}^{-3 / 2}\right)\end{array}$ & $\begin{array}{c}\phi_{\mathrm{v}}{ }^{0} \\
\left(\mathrm{~cm}^{3} \mathrm{~mol}^{-1}\right.\end{array}$ & $\begin{array}{c}\mathrm{S}_{\mathrm{v}}{ }^{*} \\
\left.\mathrm{~m}^{3} \mathrm{lit}^{1 / 2} \mathrm{~mol}^{-3 / 2}\right)\end{array}$ \\
\hline 298.15 & 599.94 & -3.142 & 303.46 & -2.554 & 165.03 & -1.919 \\
\hline 303.15 & 610.80 & -3.637 & 316.22 & -3.139 & 179.10 & -2.398 \\
\hline 308.15 & 617.06 & -3.728 & 329.25 & -3.645 & 184.24 & -2.455 \\
\hline 313.15 & 631.49 & -4.277 & 351.34 & -3.970 & 195.54 & -2.761 \\
\hline 318.15 & 638.37 & -4.489 & 361.39 & -4.205 & 207.79 & -3.276 \\
\hline
\end{tabular}

Table 3: Partial molar volume expansibilities $\left(\phi_{\mathrm{e}}{ }^{\circ}\right)$ for aluminium sulphate, aluminium nitrate and aluminium chloride in $5 \%(w / w)$ thf + water mixture at different temperatures

\begin{tabular}{lccc}
\hline Temperature(k) & $\begin{array}{c}\text { Aluminium sulphate } \\
\boldsymbol{\phi}_{\mathrm{E}}{ }^{\circ}\left(\mathbf{~ c m}^{\mathbf{3}} \mathbf{~ m o l}^{-1} \mathbf{K}^{-1}\right)\end{array}$ & $\begin{array}{c}\text { Aluminium nitrate } \\
\boldsymbol{\phi}_{\mathrm{E}}{ }^{\circ}\left(\mathbf{~ c m}^{\mathbf{3}} \mathbf{~ m o l}^{-1} \mathbf{K}^{-1}\right)\end{array}$ & $\begin{array}{c}\text { Aluminium chloride } \\
\boldsymbol{\phi}_{\mathrm{E}}{ }^{\circ}\left(\mathbf{~ c m}^{\mathbf{3}} \mathbf{~ m o l}^{-1} \mathbf{K}^{-1}\right)\end{array}$ \\
\hline 298.15 & 2.296 & 2.714 & 3.367 \\
303.15 & 2.036 & 2.514 & 3.099 \\
308.15 & 1.776 & 2.314 & 2.829 \\
313.15 & 1.516 & 2.114 & 2.559 \\
318.15 & 1.256 & 1.914 & 2.289 \\
\hline
\end{tabular}




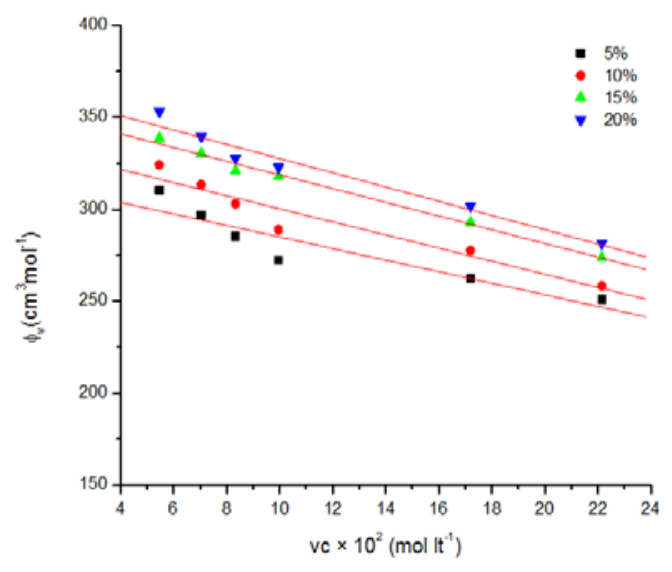

Fig. 1: Plot of $\phi_{v} V s c^{1 / 2}$ of aluminium nitrate in different compositions of THF + water at 303.15K

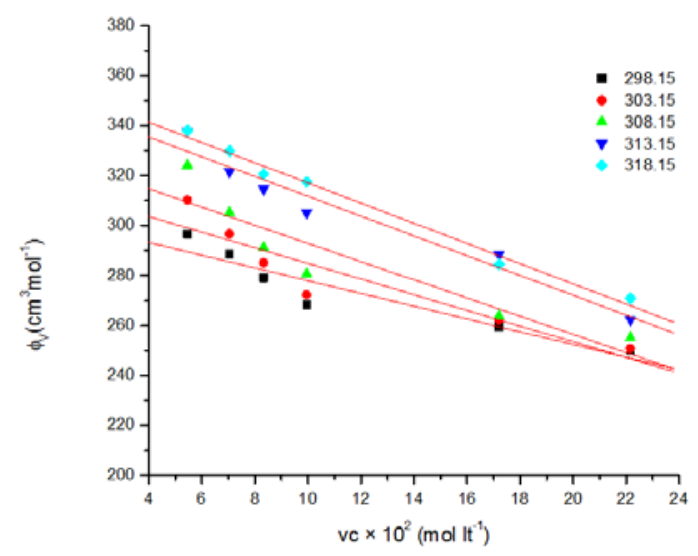

Fig. 2: Plot of $\phi_{\mathrm{v}} \mathrm{Vsc}^{1 / 2}$ for aluminium nitrate in $\mathbf{5 \%}$ binary mixture of THF + water at different temperatures

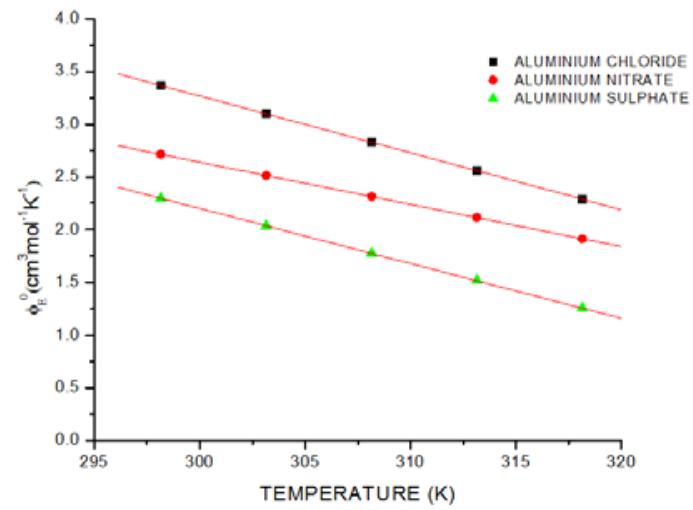

Fig. 3: Plot of $\phi_{E}{ }^{0}$ verse temperature for aluminium sulphate, aluminium nitrate, aluminium chloride in $\mathbf{5 \%} \mathrm{THF}+$ water one composition system ( $5 \% \mathrm{w} / \mathrm{w})$ has been selected for studying the effect of temperature. The experimentally determined values for the different concentrations of aluminium salts at different temperatures (298.15K - 315.15K) have been used to calculate the limiting molar volume of the salts. The plot of apparent molar volume $v$ against $\sqrt{ } \mathrm{c}$ were found to be linear with the positive slopes in water as well as in aqueous solution of THF as shown in fig. 2 for one of aluminium salts (aluminium nitrate) as sample plot.

It is evident from table 2, that the values of $\mathrm{S}_{\mathrm{v}}{ }^{*}$ are negative for aluminium salts in $5 \%$ aqueous mixture of THF at all temperatures. The negative values with rise in temperature from $298.15 \mathrm{~K}$ to $318.15 \mathrm{~K}$ of aluminium salts indicates the presence of weak ion-ion interactions and attributes the increase in the solvation of aluminium salts with rise in temperature. Also it is clear from table 2 that the values of increases with increase in temperature for the selected aluminium salts in THF + water $(5 \%$ $\mathrm{w} / \mathrm{w})$, thereby showing that ion - solvent interactions are strengthened with increase in temperature. The increase in values may be due to increase in solvation of aluminium salts with rise in temperature.

It has been found that only is not only one parameter for determining the structure making or structure breaking nature of any solute. Partial molar volume expansibilities is another parameter, which determines the making or breaking capacity of any solute in any of the solvent developed by Hepler ${ }^{15}$. The temperature dependence of $5 \% \mathrm{THF}+$ water for selected aluminium salts can be expressed by the following relations:

$\phi_{\mathrm{v}}{ }^{\circ}=-6395.90+17.80 \mathrm{~T}-0.026 \mathrm{~T}^{2}$ for aluminium sulphate

$\phi_{v}{ }^{\circ}=-2283.58+14.64 \mathrm{~T}-0.020 \mathrm{~T}^{2}$ for aluminium nitrate

$\phi_{v}{ }^{\circ}=-3177.60+19.47 \mathrm{~T}-0.027 \mathrm{~T}^{2}$ for aluminium chloride

Partial molar volume expansibilities $\stackrel{0}{\mathrm{E}}=\left[\frac{\partial_{v}^{0}}{\partial T}\right] \mathrm{P}$ , which is temperature dependence 
function of ,is calculated for the above mentioned aluminium salts by using relations 5,6 and 7 are given in table 3 . From table $3, D_{E}{ }^{0}$ values for aluminium salts at different temperatures are positive but decrease in magnitude with rise in temperature showing that these aluminium salts are not behaving like symmetrical tetra alkyl ammonium salts ${ }^{16}$ and but like common salts ${ }^{17,18}$ as in the case of common electrolytes the molar volume expansibilities should decrease with the rise in temperature. The decrease in the magnitude of $D_{E}{ }^{0}$ values indicates the absence of "packing effect"15. The plot of $\mathrm{D}_{E}^{0}$ verses temperature is found to be linear for all aluminium salts in $5 \% \mathrm{w} / \mathrm{w} \mathrm{THF}+$ water mixture as shown in fig.3.

In last few years, it has been observed by the number of workers that is not the only criterion for determining the structure making or breaking nature of any solute. Hepler ${ }^{14}$ has given a method of finding the sign of for different types of solutes in forms of long range structure making or structure breaking capacities of the solutes in aqueous solutions using the general thermodynamic relation:

$$
(\partial C p) / \partial P)=-\left(\frac{\partial_{v}^{20}}{\partial T^{2}}\right) p
$$

On the basis of equation 8, It has been found that the positive values indicates the structure making nature of solutes and negative values indicates the structure breaking nature of solutes. In our present study, it is found from equations 5 to 7 , values are negative for aluminium salts in $5 \%$ $\mathrm{THF}+$ water suggests that the all the aluminium salts taken in present study act as structure breakers in $5 \%$ aqueous solution of THF. This indicates that the addition of aluminium salts break the structure of THF + water.

\section{REFERENCES}

1. Parmar M L,;Banyal D S,; Indian J Chem, 2005, 44A.

2. Parmar M L,; Guleria M K,; J Indian ChemSoc, 2005, 82.

3. Parmar M L,; Thakur R C,; Proc. Nat. Acad. Sci. India., 2006, 76.

4. Parmar M L,; Thakur R C,; J Mol Liq., 2006, 128.

5. Parmar M L,; Attri S C,; J Mol Liq, 2007, 136

6. Sarkar B K,;Sinha B,; Roy M N,; Russian J of Physical Chem, 2008, 82.

7. Bhattaraiand A,:Das B,; J. Nepal Chemistry, 2009, 23.

8. Yousuf M A,; Salim Reza K M ,; Daffodil International University $\mathrm{J}$ of Science and

a. Technology, 2009,4.

9. Rajagopal K,;Gladson S E,; J. Chem. Thermodynamics 2011, 43.

10. Shashi Kant,;Sharma Kamini,; ChemSci
Trans, (2012)

11. Singh, R.; Yadav, Y.; Orient.J.Chem, 2013,29(4), 1661-1664.

12. Covinton A K,;Dickison T, Physical Chemistry of Organic Solvent Systems,

a. (Plenum, New York) 1973.

13. Ward G K,;Millero F J,; J Chem 1974., 3.

14. Millero $F \mathrm{~J}$, in structure and Transport Processes in water and Aqueous Solution,

a. edited by R A Horne, (Wiley - inter Science, New York) 1971, chap. 13, p 521.

15. Hepler L G,; Can J Chem 1969., 47.

16. Millero $F \mathrm{~J}$, in structure and Transport Processes in water and Aqueous Solution,

a. edited by R A Horne, (Wiley - Inter Science, New York) 1971, chap.15, p 622.

17. Milllero,F.J.; Drost Hansen, WJ.P phy.Chem.72.(1968)

18. Millero F.J,; Chem.Rev 1971, .71. 